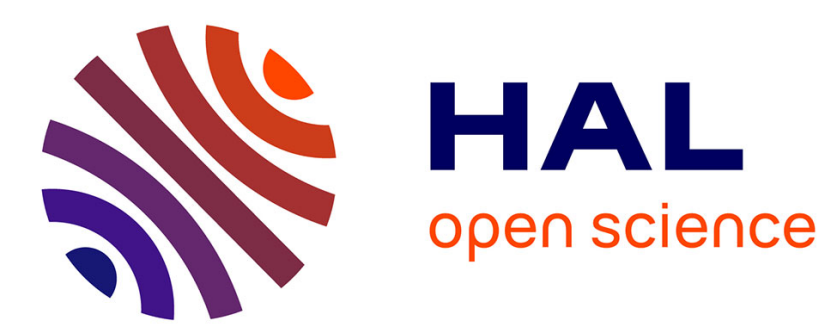

\title{
Fracture surface energy and craze fibril stress in PMMA in water
}

\author{
R. Schirrer, L. Josserand, P. Davies
}

\section{To cite this version:}

R. Schirrer, L. Josserand, P. Davies. Fracture surface energy and craze fibril stress in PMMA in water. Journal de Physique IV Proceedings, 1993, 03 (C7), pp.C7-1553-C7-1557. 10.1051/jp4:19937242 . jpa-00251880

\section{HAL Id: jpa-00251880 https://hal.science/jpa-00251880}

Submitted on 1 Jan 1993

HAL is a multi-disciplinary open access archive for the deposit and dissemination of scientific research documents, whether they are published or not. The documents may come from teaching and research institutions in France or abroad, or from public or private research centers.
L'archive ouverte pluridisciplinaire HAL, est destinée au dépôt et à la diffusion de documents scientifiques de niveau recherche, publiés ou non, émanant des établissements d'enseignement et de recherche français ou étrangers, des laboratoires publics ou privés. 


\title{
Fracture surface energy and craze fibril stress in PMMA in water
}

\author{
R. SCHIRRER, L. JOSSERAND and P. DAVIES*
}

ICS (CRM-EAHP), 4 rue Boussingault, 67000 Strasbourg, France

* IFREMER, BP. 70, 29280 Plouzane, France

Polymethylmethacrylate (PMMA) is often used as a material for portholes in submarine applications. Therefore, the fracture properties of dry and wet PMMA. in water and/or under hydrostatic pressure are of great importance. In this study compact tension specimens immersed in water have been used on a tensile machine and crack tips have been observed by means of optical interferometry during propagation. Fracture stress intensity factors, and plastic zone size have been measured as a function of loading time and crack speed in water. The results have been rationalized in terms of craze stress and craze life time at the crack tip, and in terms of a stress activated process of craze fibril growth and rupture. It has been shown that water increases the fracture toughness, in spite spite of the fact that the microscopic craze stress and craze fibril life time decrease at the crack tip.

\section{1-INTRODUCTION:}

Crazing and fracture properties of polymers are strongly influenced by the environment: stress cracking and crazing due to chemical effects, crack-tip plasticizing by liquids or solvent gases, surface energy lowering by tensioactive liquids, molecular mobility modification by hydrostatic liquid pressure, etc...Environmental rupture has been widely studied, particularly from the experimental point of view, and general rules are known concerning chemical and physical effects of gases and liquids on polymer fracture. Nevertheless, most of these studies use very simple fracture tests to quantify the environmental effects, and although rather coarse values of environmental assisted fracture toughness are known, real time microscopic crack-tip behaviour under harsh environmental conditions has been much less studied. This is because special experimental equipment is required to investigate the material in this case. References 1 to 7 give an overview on the subject.

In the present study, the single craze at a crack-tip propagating in PMMA in air and water has been investigated on a microscopic scale. Local material properties like craze fibril stress and craze fibril life-time have been investigated by means of optical interferometry.

The material used was Altuglas PMMA from Altulor company (cast sheets). The sheets were $4,2.5$ and $1.5 \mathrm{~mm}$ thick. The advantage of this material is that there are already a great number of general mechanical property measurements available from many authors. It was measured that water decreases the mechanical properties of PMMA by means of a plasticizing mechanism, but the changes are rather smal1. As shown below, the fracture properties are much more affected than the small deformation mechanical properties 


\section{2-FRACTURE PROPERTIES IN WATER}

All results shown below concern crack and/or craze propagation in dry PMMA immersed in water during the propagation. This is the most realistic case in practical use, due to the very low water diffusion coefficient combined with the fact that the PMMA components are mainly in air and only occasionally immersed. Therefore, the water diffusion kinetics concern mainly the very narrow crack-tip zone.

Fracture toughness has been measured with $30 \mathrm{~mm}$ width standard Compact Tension Specimens. The crack and craze velocity was controlled with a telescope fitted onto a camera. The sample was illuminated with white light between two crossed polarizers to vizualise the birefringence due to the stress fields. Smaller samples ( $10 \mathrm{~mm}$ width) were observed by means of real time optical microscopic interferometry [8]. The samples were immersed in water by means of a small transparent tank fitted to the grips. Figure 1 shows the experimental setup. The samples were pre-cracked with a milled saw cut, and subsequently the crack was sharpened (in air) with a $100 \mathrm{~Hz}$ fatigue loading.

- Crack-tip visualization: figure 2 shows by means of birefringence the crack and craze tips. Both tips can be separated and individually followed during the process if the craze (or plastic zone) is long enough to be resolved by the optical telescope.

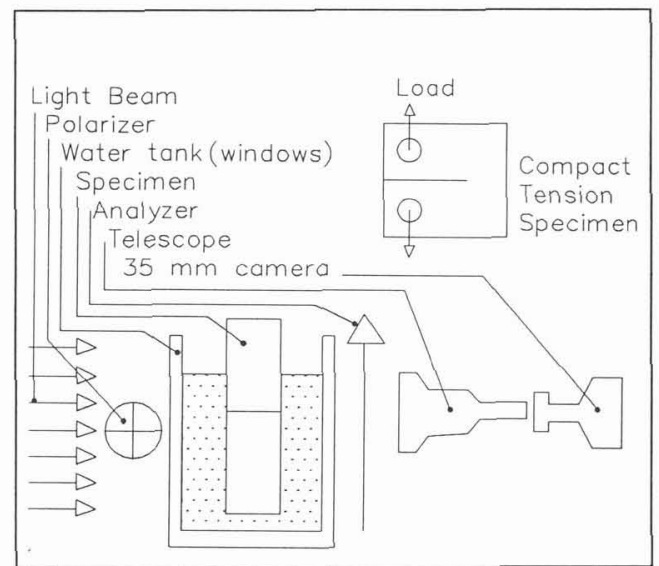

Figure 1: Tensile machine setup

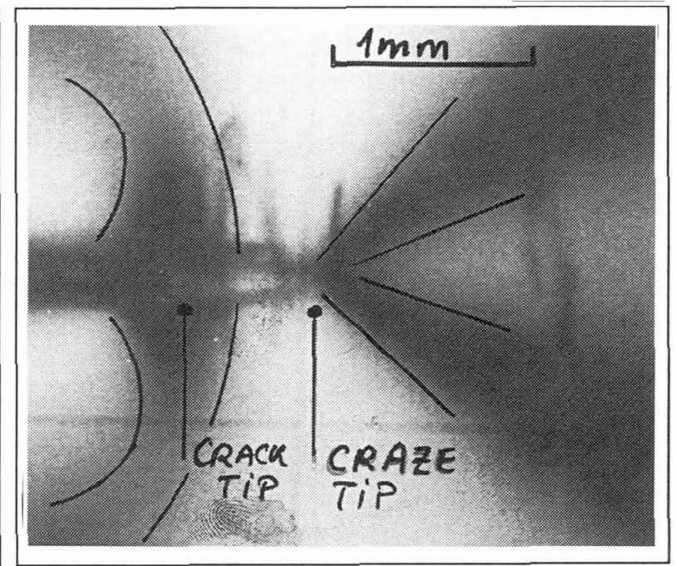

Figure 2: Crack tip between polarizers showing plastic zone tip.

${ }^{-K}{ }_{1}$ versus velocity: Standardized fracture toughness measurements do not need the monitoring of the crack speed or length in a real time experiment. Nevertheless, the results of such simplified measurements are rather dispersed, one of the major reason beeing the unknown crack-tip starting point on the load-deflection curve. Moreover, it is well kown that the fracture toughness depends strongly on the crack velocity, which may vary over several decades at the propagation starting point. More accurate results are obtained when considering the fracture energy as a function of crack speed for brittie material, or as a function of crack length for ductile materials. In the case of brittle materials like PMMA, the crack-tip velocity must be kept constant until quasi-stationary propagation is reached. The $K_{1}$ or $G_{1}$ value obtained for the particular velocity is then an intrinsic material property. Figure 3 shows the values of $K_{1}$ versus velocity for a crack-tip propagating in air compared to that propagating in water.

The toughness in water is about twice that in air, specially at low propagation speed. It appears that the scatter in water is much larger than that in air. Careful examination of the experimental procedure showed that the loading 
history (i.e. loading rate) influences strongly the $K_{1}$ value achieved as a function of crack speed. This is in contradiction with the behavior in air.

$-K_{1}$ versus loading rate: figure 4 shows the toughness as a function of crack speed, but with a controlled loading rate. Surprisingly, a one decade change in loading rate doubles the toughness in the $0.001 \mathrm{~mm} / \mathrm{s}$ velocity range. Consequently the $K_{1}$ versus velocity is no longer an intrinsic material property. There exists a knee in the $K_{1}$ curve, which correspond to the velocity above which the crack-tip propagates steadily without increasing the plastic zone size at its tip.
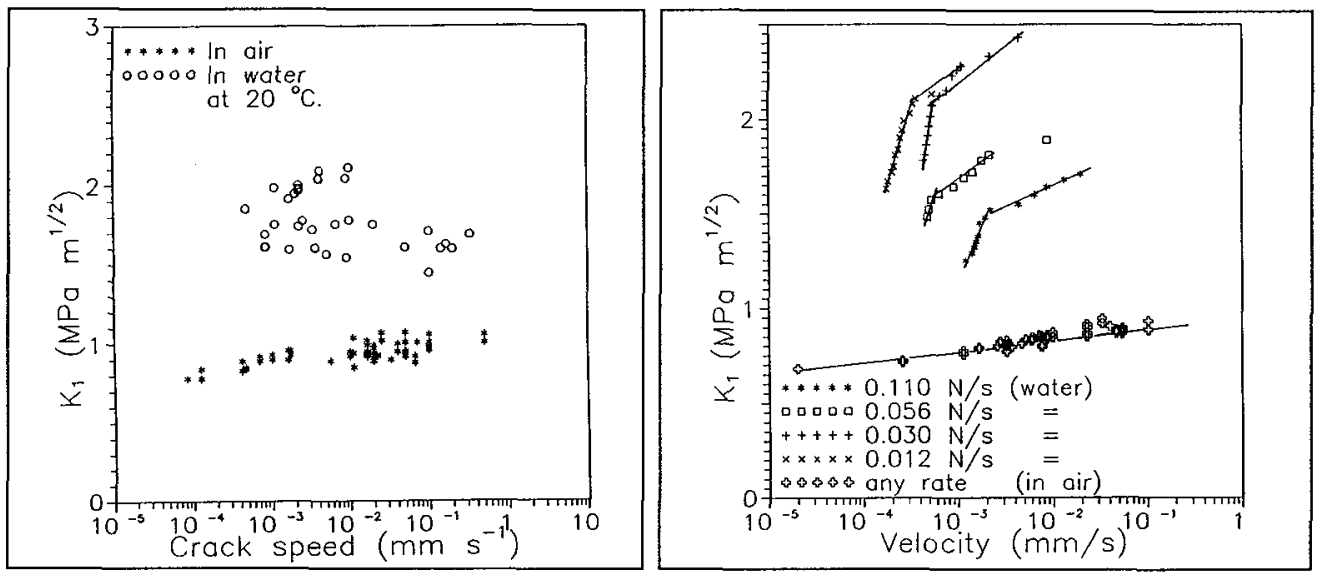

Figure 3: Toughness versus crack speed Figure 4: Toughness versus loading rate.

-Plastic zone size versus loading rate: the toughness varying with loading rate indicates that the plastic zone at the crack tip depends probably also on loading rate. Figure 5 shows the length of the plastic zone as measured with both techniques. The size increases with decreasing loading rate: at 10 wates, the crack tip yields and crack-tip blunting decreases the local stress intensity. Consequently, a higher external stress is needed to propagate the crack. Finally, the plastic zone size stabilizes and the cracktplastic zone system propagates steadily. Interferometric experiments showed that the plastic zone is a craze, as it is in air, where its size is loading rate independent.

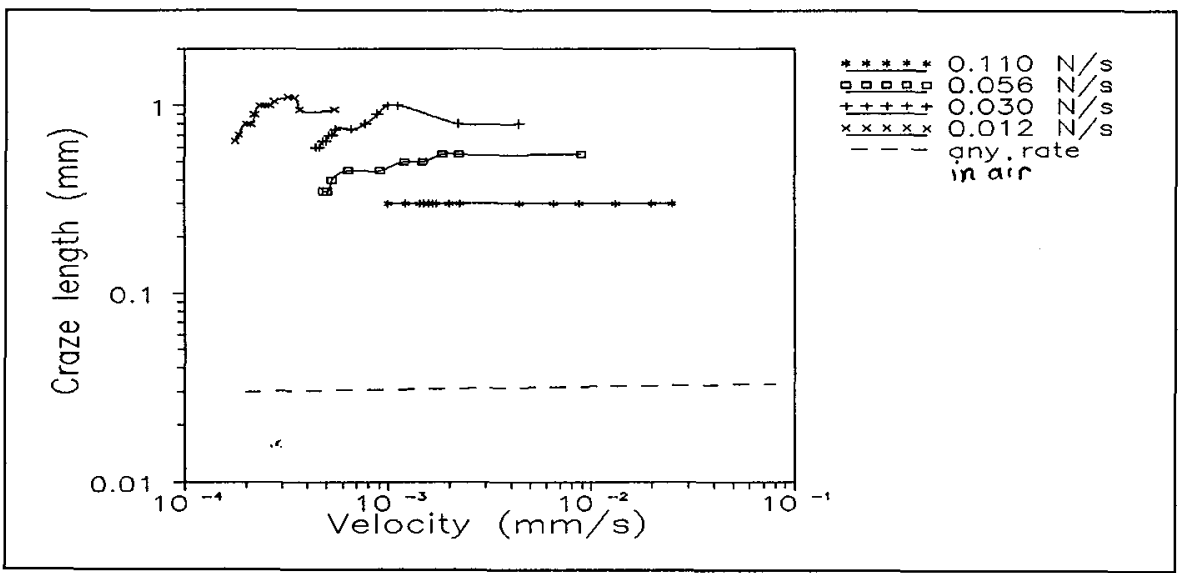

Figure 5: Craze length versus versus loading rate. 


\section{3. - CRACK TIP MODEL, CRAZE MICROMECHANICS}

The material near the loaded crack tip is subjected to a stress field which is divergent at the tip. Due to that field, the material is damaged near the tip, and produces either a craze, or shear lips, or a complex structure of damaged material. In the case of the craze, which corresponds to PMMA in water, stresses and strains in the vicinity are known [9]. In particulary, it has been shown that the stress applied to the craze fibrils is rather constant (with a small peak at craze tip and end), and that its mean value $\sigma_{c}$ is a function of the stress intensity factor $K_{1}$ and craze length $S$ :

$\sigma_{c}^{2}=\pi K_{1}^{2} / 8 S$

Craze fibrils originate from bulk by cavitational mechanisms at the craze tip, and subsequently they grow mainly by extracting fresh material from the bulk. To some extent, they also grow by an extension mechanism. As they are subjected to a stress they break after a while. Each fibril is subjected to the stress during the time it takes for the craze to move over one craze length [9]. In a stationary propagation this time $\tau_{c}$, which depend on the stress $\sigma_{c}$, is function of the crack-craze velocity $\mathrm{v}_{\mathrm{c}}$ :

$\tau_{\mathrm{c}}\left(\sigma_{\mathrm{c}}\right)=\mathrm{S} / \mathrm{v}_{\mathrm{c}}$

and hence

$$
K_{1}\left(v_{c}\right)=\left(8 r_{c} v_{c} / \pi\right) \sigma_{c}^{1 / 2}
$$

Craze length, propagation velocity, and $K_{1}$ values are recorded during the experiments. Hence, the local, intrinsic material properties governing fibril extraction at the craze tip, $\sigma_{c}$ and that governing fibril rupture, $\tau_{c}\left(\sigma_{c}\right)$ can be inferred.

Figure 6 shows the craze fibril life time as a function of the stress applied to the fibrils. It appears that the loading rate is no longer a relevant parameter, as it was in the $K_{1}$ or $S$ plot. This proves that the fibril life time is an intrinsic material property, as it is geometry independent. The influence of the loading rate on $K_{1}$ and $S$ values is due to the fact that during the measurement, macroscopic stationary rupture conditions are not reached. Therefore, the transient conditions under which $K_{1}$ and $S$ were measured are variable and unknown. Locally, at the fibrils level, even under these macroscopic transient conditions, real intrinsic material properties govern the rupture. The plot shows also that the fibrils life time in water is 3 orders of magnitude lower than that in air at a given stress on the fibrils.

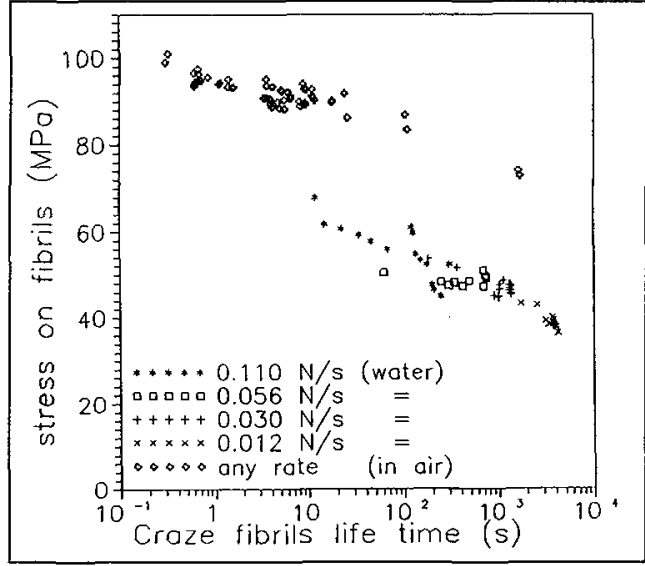

Figure 6: Fibril life time (all loading rates are plotted)

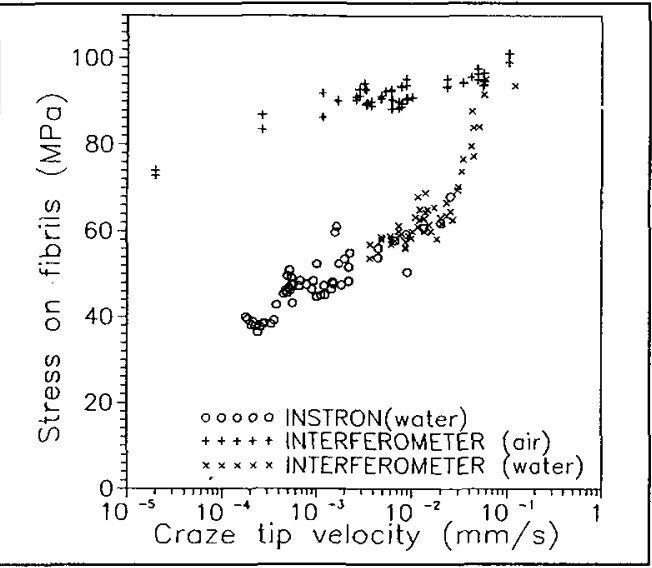

Figure 7: Craze tip velocity (a)1 loading rates are plotted) 
Figure 7 shows the craze tip velocity as a function of the stress on the fibrils. This is the second relevant intrinsic material property, governing the cavitation of the bulk leading to fibrils. Again, the loading rate is no longer a relevant parameter for the same reasons. The velocity in water is also about 3 orders of magnitude faster than in air, and the tensile machine measurement overlap very well the interference measurements. There is an interesting zone at $10^{-1} \mathrm{~mm} / \mathrm{s}$, where the values in water rejoin these in air. This corresponds to the velocity above which water cannot flow fast enough around the fibrils to reach the craze tip, or diffuse fast enough into the fibrils to soften them.

Figure 8 shows in detail the transition zone, with both craze tip and crack tip velocities as a function of stress. For each value of stress, both velocities were measured. At low velocity, in water, the crack propagates about 10 times slower than the craze! Near the transition velocity, both crack and craze propagate at the same velocity, in a steady-state manner. This explains clearly the complicated behavior of $K_{1}$ versus velocity in water: $K_{1}$ depends on craze length $S$ (eq. 3), which in turn depends on both craze and crack speed, which are not the same: there is no steady-state crack-craze propagation at low velocity in water. Hence $K_{1}$ cannot be uniquely defined as a function of velocity.

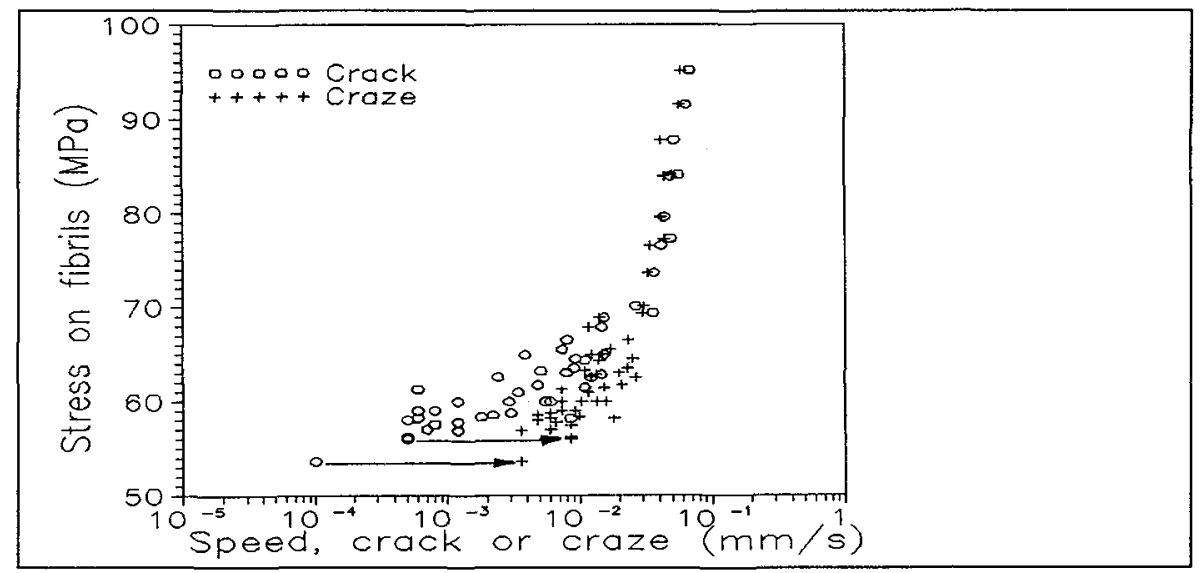

Figure 8: Craze and crack tip velocity versus craze stress.

\section{CONCLUSION}

There are 3 velocity (or time) zones where different mechanisms control the crack-craze growth. Figure 7 shows that at low velocity water plasticizes fibrils and flows quasi instantaneously to the craze tip. The rupture is controlled by external load and crack-tip micromechanics as in air, but the stresses involved are lower. Like in air, fibril growth activation volumes and energies in water may be inferred from experiment [8]. On the other hand, at high velocity, water does not plasticize the fibrils at all, nor does it flow to the craze tip, and fracture occurs like in air. In the mid range of velocity, water diffusion processes in the fibrils and/or water flow mechanisms are dominant and control the crack-craze propagation velocity. Water diffusion or flow rules may be inferred from experiments.

[1] Y.M. MAI, J. Mater. Sci. 10(1975)943-954

[2] D. PUTZ and G. MENGES, The British Polymer Journal, 10(1978)69-73

[3] P.J. BURCHILL and R.H. STACEWICZ, J. Mater. Sci. Letters 1(1982)446-450

[4] R.G. HILL et.al. J. Mater. Sci. 19(1984)1904-1916

[5] J. SHEN et.al. Polymer, 26(1985)511-518

[6] L.S. SMITH and J.A. SAUER, Plastics and Rubber Processing 6(1986)57-65

[7] V.A. KEFALAS and A.S. ARGON, J. Mater. Sci. 23(1988) 253-258

[8] R. SCHIRRER and G. GALLERON, Polymer, 29(1988)634-640

[9] P. TRASSAERT and R. SCHIRRER J. Mater. Sci. 18(1983)3004 